\title{
ESTIMATING THE INCOME LOSS OF DISABLED \\ INDIVIDUALS: THE CASE OF SPAIN
}

Maria Cervini-Plá*

Jose I. Silva**

Judit Vall-Castello***

October 2012

\begin{abstract}
In this paper, we present both a theoretical and an empirical model in order to identify the effects of disability on wages. In the theoretical model we assume that the wage gap of a disabled worker depends on a permanent and a transitory productivity gap and the model predicts that the wage gap will be lower after gaining some work experience in the new job. We test this theoretical hypothesis using an exogenous disability shock and matching methods associated with treatment effect techniques for policy evaluation. In all our specifications, we find that the reduction of the wage for the disabled is between 293 and 342 euros per month expressed in constant terms at 2010 prices (21-24\% of the average wage of disabled workers) but this reduction is more than offset when we take into account both the disability benefits and the wage. As predicted in the theoretical model, we observe that the pay gap between the disabled and the non-disabled individuals falls over time once the transitory drop in productivity disappears. However, we observe a constant wage gap that remains over time and that corresponds to the permanent fall in productivity predicted by the theoretical model.
\end{abstract}

\footnotetext{
Universitat de Girona, Spain. Email: maria.cervini@udg.edu

. Universitat de Girona, Spain. Email: jose.silva@udg.edu

... Universitat de Girona \& Centre for Research in Economy and Health, Universitat Pompeu Fabra. Email: judit.vall@udg.edu
} 


\section{Introduction}

During the last years, disability policies have attracted particular attention in OECD (Organization for Economic Co-operation and Development) countries both because they represent an important source of government expenditure and because societies are becoming more and more concerned about the need to strengthen the integration of disabled individuals in the society.

For the case of Spain, the strong incidence of the current economic crisis will probably push many employed people with a disability out of the labour market as this group of individuals represents one of the most vulnerable groups in the society. Therefore, several international organizations recommend governments to foster reforms that will help disabled individuals maximize their work capacity and keep or find jobs. Not only international organizations are advocating for this strategy but also several studies and organizations of people with disabilities have stressed the need to promote the labor market integration of disabled individuals as a way of facilitating their broader integration in the society.

For these reasons, the possibility of increasing the number of disabled people that work is regarded as a good way to decrease the pressures on the financial stability of the social security system as well as to reach the social integration of disabled individuals.

However, a closer look into the data reveals that this objective is far from being reached in most developed countries and employment rates of disabled individuals are particularly low for the case of Spain.

As it can be seen in figure 1 below, employment rates of self-reported disabled individuals in Spain remained quite low at a 35\% level even if the GDP growth has been quite high at around 2-6\% between 1996 and 2007. ${ }^{12}$ This is one of the lowest rates in the OECD, where employment rates for self-reported disabled individuals are $45 \%$ in the UK, $40 \%$ in Australia, $50 \%$ in Luxembourg, $45 \%$ in Norway or $52 \%$ in Switzerland.

\footnotetext{
${ }^{1}$ This data is taken from a report from the OECD and it is, therefore, comparable for these countries.

2 The general employment rate increased by $7 \%$ between 2001 and 2007 . In turn, 3.5\% of the Spanish population is receiving disability benefits in 2010 .
} 
Figure 1. Employment rates by disability status in the late-2000s

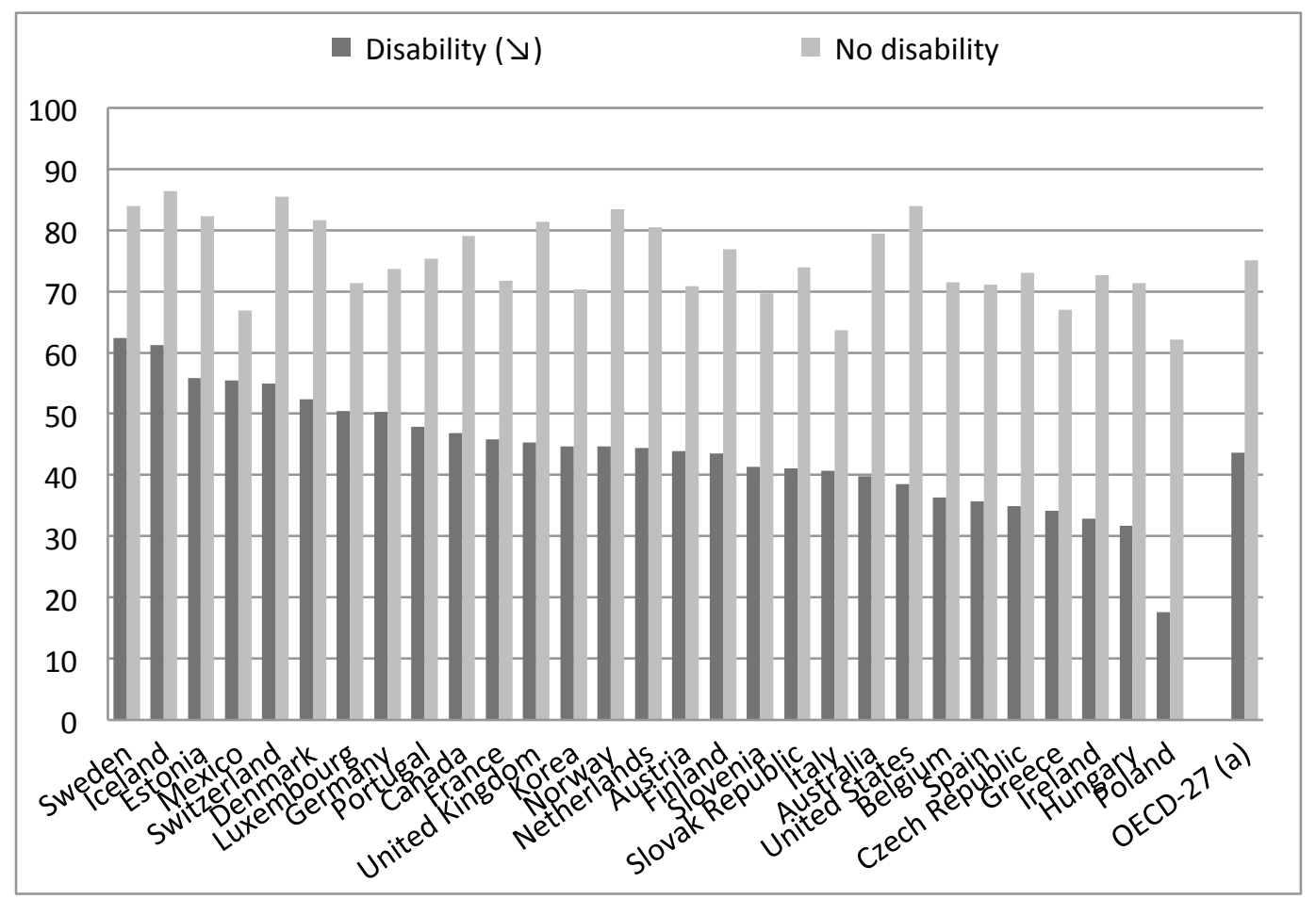

Taken from OECD 2009. Source: EU-SILC 2007 (wave 4), except: Australia: SDAC (Survey of Disability and Carers) 2003; Canada: PALS (Participation and Activity Limitation Survey) 2006; Denmark: LFS 2005; Korea: National Survey on Persons with Disabilities, 2005; Mexico: ENESS (National Survey of Employment), 2004; Netherlands: LFS 2006; Norway: LFS 2005; Poland: LFS 2004; Switzerland: LFS 2008; United Kingdom: LFS 2006; United States: SIPP (Survey of Income and Program Participation) 2008.

These very low employment rates for the disabled in Spain occur despite several policies (both anti-discrimination and labour promotion policies) that aim at ensuring that disabled individuals have the same labour market opportunities than their nondisabled counterparts. Therefore, apart from the evidence that disabled individuals have lower employment rates, in this paper we also want to explore whether they have another disadvantage in terms of labour market opportunities and we want to test whether the onset of an unexpected disabling condition does also entail reduced earnings for the disabled. At the same time, if we find empirical evidence that this is indeed the case for the disabled in Spain, we are also interested in analysing whether this wage gap with respect to their non-disabled counterparts is permanent in time or is reduced over time. In other words, we want to know if disabled individuals are able to "catch up" in terms of wages lost due to the disabling condition. 
There are a few papers in the literature that have tried to estimate the dynamic impact of disability on wages, addressing specifically the issue of whether this wage gap decreases or not over time. Using self-reported information about disability in the US, Charles (2003) analyses the evolution of expected earnings of worked-limited disabled men over time, both before and after the individual suffers onset. He finds that expected earnings show a sharp drop around the data of onset and then recover during the following periods. In a more recent study and using the same database, Mok et al. (2008) find much larger losses from disability than those published in Charles (2003). ${ }^{3}$ Due to the characteristics of the data they use, these papers are not able to distinguish between different types of disability. As Charles (2003) mentioned, the type of disability such as accident or illness may have different effects in the temporal pattern of earning losses as well as it may raise some endogeneity concerns. In our paper we make use of a Spanish administrative database that will allow us to go a step further and identify the source of the disabling condition so that we can have a measure of an exogenous disability shock that does not affect earnings before the date of onset.

For the case of Spain, Garcia-Gomez and Lopez-Nicolás (2006) make use of the European Community Household Panel dataset to try to estimate the effect of past health events on current changes in labour status. Using a matching technique, their results show that there are important effects of disability shocks on income as total individual income is reduced. In particular, they estimate the reduction in personal income to be 1648 euros/year in the year of the disability shock and 1740 euros for the second year. They find that the drop in labour income is not fully compensated by social security transfers. Due to the small sample sizes for the treatment and control groups, the authors are not able to estimate the effects on subsequent periods.

The very recent administrative database that we use allows us to go a step further than the work in Garcia-Gomez and Lopez-Nicolás. First, we present a more updated study of the effects of disability on wages (from 1996-2010) than the paper by Garcia-Gomez and Lopez-Nicolás (1994-2001). Second, and due to the longer time span of our data, we are able to uncover whether disabled individuals are able to "catch up" in terms of wages with respect to their non-disabled counterparts. Third, we are able to identify the source of the disabling condition so that we can have a measure of a disability shock

\footnotetext{
${ }^{3}$ This result is in line with the evidence found by Meyer and Mok (2006) in a previous study.
} 
that is clearly exogenous and finally, we also present a theoretical model to derive some predictions of the impact of disability on wages and the evolution of this impact over time that we later test in the empirical section.

Therefore, in this paper we present both a theoretical model and an empirical model in order to identify the effects of disability generated by an accident on wages and the channels underlying this relationship. In the theoretical wage gap model we assume that the wage gap of a disabled worker depends on a permanent and a transitory productivity gap. The permanent component is due to the disability condition after the disability shock while the transitory component is related to the presence of assimilation costs for being in a different job or professional activity, which reduces the implicit bargaining power of the disabled employee. Thus, the model predicts that the wage gap will be lower after some work experience in the new job but that the permanent wage gap component will remain.

We test this theoretical hypothesis with an empirical model in which we want to estimate how much wages change, on average, for those individuals who become disabled due to an exogenous disability shock, compared to the hypothetical state of not having received the disability shock that causes the disabling condition. We also estimate the evolution of this wage gap over time. As one of the main problems in measuring this change is the endogeneity of the disability status and the wages, we only include in our sample individuals that become disabled due to an accident (which is an exogenous disability shock) and estimate the Average Treatment Effect on the Treated (ATET). Therefore, we want to know what would have happened to that individual if he or she had not become disabled (counterfactual) and, as we do not have that information, we make use of matching methods to allow for the counterfactual approach, associated with treatment effects techniques for program evaluation. In particular we estimate the effect of disability on wages by matching on the propensity score.

In all our specifications, we find that the reduction of the wage for the disabled is between 293 and 342 euros per month expressed in constant terms at 2010 prices (which represents between $21 \%$ and $24 \%$ of the average wage of disabled workers) but this reduction is more than offset when we take into account both the wage and the disability benefits that they get. For the entire group of disabled individuals (the ones 
that work and the ones that do not have a job), we still find a drop in income for the disabled relative to the non-disabled individuals. Therefore, those individuals would have obtained a higher income by just working in the hypothetical case of not having suffered the disabling condition. Finally, we observe that the pay gap between the disabled and the non-disabled individuals falls over time as predicted in the theoretical model so that the transitory drop in productivity is disappearing. However, we observe a constant wage gap component associated with the permanent fall in productivity predicted in the theoretical model that remains over time.

There are also a number of studies that analyze the effects on the income loss of disabled individuals in other countries. For example, Lechner and Vazquez-Alvarez (2011), using matching methods, find that there is no statistically significant evidence for a reduction in income due to disability for the case of Germany and so they conclude that the German social security system is able to mitigate the economic disadvantages of the disabling condition. Contoyannis and Rice (2001) study a similar thing for the UK using the British Household Panel Survey and find that positive self-assessed health increases the hourly wage for females while reduced psychological health reduces the hourly wages for males. Also for the UK, Kidd et al. (2000) focus on the differences in labour market outcomes between disabled and able-bodies individuals and they confirm the presence of substantial wage and participation rate differences between the two groups. Their estimates suggest that, on average, the disabled earn 14,8\% less than the able bodied. Restricting the sample to include only males from the UK, Walker and Thomson (1996) estimate a very small effect of disability status on wages once they take into account the endogeneity of schooling on health. Lundborg et al. (2011) apply a diff-in-diff approach to Swedish data and find that the effects of a disability shock are stronger in terms of reduced labour earnings for individuals with low education and this effect is stronger for older individuals.

The paper proceeds as follows: section 2 describes the specificities of the Spanish disability System. Section 3 introduces the theoretical wage gap model. Sections 4 and 5 present the empirical strategy and the database, respectively. Section 6 constructs the treatment and control groups and section 7 presents some descriptive statistics. Finally, the main results are summarized in section 8 and some conclusions are derived in the final part of the paper. 


\section{The Spanish Disability System}

In order to solve the endogeneity problem between the disability and the labour market status and the numerous problems related to self-reported measures of health or disability status, for this paper we will only include in our sample individuals that become disabled due to an exogenous disability shock (an accident) and that begin receiving disability benefits due to this disability shock. With this sample selection restriction, we make sure that the disability shock received by the individual is exogeneous as an accident is an unexpected event and it is externally assessed by a medical team before receiving the benefits.

The disability system in Spain distinguishes between two types of permanent disability benefits: i) contributory, which are given to individuals who have generally contributed to the Social Security system before the onset of the disabling condition; ii) and noncontributory, which are given to individuals who are assessed to be disabled but have never contributed to the Social Security system (or do not reach the minimum contributory requirement to access the contributory system). Non-contributory disability benefits are means-tested and managed at the regional level. ${ }^{4}$

The size of the non-contributory system is relatively small compared to the contributory system (197,126 individuals received non-contributory disability benefits in 2009, while 920,860 received contributory benefits during the same year). The amount of benefits received is also smaller in the non-contributory case (the average non-contributory pension is 417.09 Euros/month compared to an average contributory disability pension of 831.49 Euros/month). As we want to assess the effect of disability on wages, in the remaining of the paper we focus only on the permanent contributory disability system in Spain.

The Social Security defines the permanent contributive disability insurance as the economic benefits to compensate the individual for losing a certain amount of wage or professional earnings when affected by a permanent reduction or complete loss of his/her working ability due to the effects of a pathologic or a traumatic process derived from an illness or an accident.

\footnotetext{
${ }^{4}$ Income is evaluated yearly. The income threshold in 2010 was set at 4,755.80 Euros/year for an individual living alone. This amount is adjusted if the individual lives with other members.
} 
In order to capture the different situations in which a person can be after suffering from a disabling condition, the Spanish Social Security administration uses a classification of three main degrees of disability that depend on the working capacity lost: ${ }^{5}$

(i) Partial disability (57\% of claimants): the individual is impaired to develop all or the fundamental tasks of his/her usual job or professional activity, but he/she is still capable of developing a different job or professional activity.

(ii) Total disability ( $40 \%$ of claimants): the individual is impaired for the development of any kind of job or professional activity.

(iii) Severe Disability (3\% of claimants): Individuals who, as a result of anatomic or functional loses, need the assistance of a third person to develop essential activities of daily living such as eating, moving, etc.

The eligibility requirements and the pension amount depend on the source of the disability (ordinary illness, work related or unrelated accident or occupational illness), the level of the disability and the age of the onset of the disabling condition. Table 1 summarizes the main parameters of both the eligibility criteria and the pension formula. With respect to eligibility, the number of years of contributions required depends on the age of the onset of the disabling condition for common illness while there are no contributory requirements if the health impairment is due to either an accident or an occupational illness.

The total amount of the pension is obtained by multiplying a percentage, which varies depending on the type of pension and the degree of disability (as shown in the last rows of Table 1) to the regulatory base, which depends on the source of the disability and on previous salaries. ${ }^{6}$ The percentage is $55 \%$ or $75 \%$ for partial disability beneficiaries, $100 \%$ for total disability and $150 \%$ for severe disability.

The number of years included in the regulatory base depends on the source of the disability; for common illness the regulatory base is calculated by dividing by 112 the wage in the last 96 months ( 8 years) before becoming disabled. When the source of the disability is a work-unrelated accident, the regulatory base is calculated by dividing by 28 the wage in the last 24 months before becoming disabled. The individual can choose these 24 months from the last 7 years of work. For work-related accident or

\footnotetext{
${ }^{5}$ There is a fourth degree of disability benefits (permanent limited disability) but this type of benefits is already extinguished and it only consists on a one-time lump-sum payment.

${ }^{6}$ Benefit=Regulatory Base * Percentage
} 
professional illness, the regulatory base is calculated by dividing by 12 the wage in the last 365 days before becoming disabled. ${ }^{7}$

Table 1. Summary of the parameters to calculate permanent disability pensions.

\begin{tabular}{|c|c|c|c|}
\hline & Ordinary Illness & $\begin{array}{l}\text { Work-unrelated } \\
\text { Accident }\end{array}$ & $\begin{array}{l}\text { Work-related } \\
\text { Accident or } \\
\text { Professional } \\
\quad \text { Illness }\end{array}$ \\
\hline \multirow[b]{2}{*}{ Eligibility } & $\begin{array}{l}\text { Age }>=31 \text { : } \\
\text { Contributed } 1 / 4 \text { time } \\
\text { between } 20 \text { years old } \\
\text { and disabling condition. } \\
\text { Minimum of } 5 \text { years }\end{array}$ & \multirow{2}{*}{$\begin{array}{l}\text { No minimum } \\
\text { contributory } \\
\text { period required }\end{array}$} & \multirow{2}{*}{$\begin{array}{l}\text { No minimum } \\
\text { contributory } \\
\text { period required }\end{array}$} \\
\hline & $\begin{array}{l}\text { Age }<30 \text { : } \\
\text { Contributed } 1 / 3 \text { time } \\
\text { between } 16 \text { years old } \\
\text { and disabling condition. } \\
\text { No minimum number of } \\
\text { years required }\end{array}$ & & \\
\hline $\begin{array}{l}\text { Regulatory } \\
\text { Base }\end{array}$ & $\begin{array}{l}\text { Average wage last } 8 \\
\text { years of work }\end{array}$ & $\begin{array}{l}\text { Average annual } \\
\text { wage of } 24 \\
\text { months within the } \\
\text { last } 7 \text { years of } \\
\text { work }\end{array}$ & $\begin{array}{l}\text { Average wage } \\
\text { last year of work }\end{array}$ \\
\hline \multirow{3}{*}{$\begin{array}{l}\text { Percentage } \\
\text { applied to the } \\
\text { regulatory base }\end{array}$} & \multicolumn{3}{|c|}{$\begin{array}{l}\text { Partial Disability: } 55 \% \\
\text { Individuals older than } 55 \text { with difficulties to find a job due to lack } \\
\text { of education or characteristics of the social and labor market of } \\
\text { the region where they live: } 75 \%\end{array}$} \\
\hline & \multicolumn{3}{|l|}{ Total Disability: $100 \%$} \\
\hline & \multicolumn{3}{|c|}{ Severe Disability: $100 \%+50 \%$} \\
\hline
\end{tabular}

\section{Theoretical Model: A wage gap model between a non-disabled and a disabled worker}

We consider a wage determination setting for both non-disabled (n) and for partially disabled individuals (d). The total output of the firm generated by a non-disabled worker is $p_{t}$, where the subscript $t$ refers to time. In turn, the labor productivity of a disabled worker is reduced by a constant proportion $\varepsilon$. According to the Spanish disability system legislation, a partial disabled individual must work in a different job or

\footnotetext{
${ }^{7}$ There was a reform in the calculation of the level of disability benefits for ordinary illness introduced in 2008. After the reform, there was a percentage that depended on the number of years contributed to the system that was multiplied by the regulatory base. However, this change only affects individuals whose source of the disability is an ordinary illness and, in our sample, we only include individuals that are disabled due to an accident. Therefore, this reform does not affect our sample.
} 
professional activity to the one that he had before becoming disabled. Along this line, we also assume the presence of a productivity gap, $\theta_{t}$, related to the assimilation costs of working in a different job or professional activity. ${ }^{8}$ This gap may disappear after a certain period spent working in the new job. The firm pays wages $w_{t}^{d}$ and $w_{t}^{n}$ for each type of worker. As long as the firm employs a worker, the total payoff of the firm is $p_{t}-w_{t}^{n}$ for a non-disabled worker and $p_{t}\left(1-\varepsilon-\theta_{t}\right)-w_{t}^{d}$ for a disabled one.

The firm and a worker are matched together under the presence of labor market frictions. Thus, if the firm and the worker separate, they will have to go through an expensive process of search before meeting another partner. Because of the presence of these labor market frictions the worker and the firm bargain over the wage. If they disagree, both types of workers receive an outside wage, $b_{t}$, and the firm produces nothing. The parameter $b_{t}$ includes unemployment benefits and some level of home production net of search costs. Moreover, disabled individuals also receive partial disability pensions that are non-contingent to the working status. This pension is equivalent to a proportion, $\alpha$, of their average wage for the years previous to the exogenous disability shock, $w_{0}^{d}$.

We assume that wages are determined by Nash bargaining, where the worker has bargaining power $\beta$. The wages derived from the Nash bargaining solution are the $w_{t}^{d}$ and $w_{t}^{n}$ that maximize the weighted product of the worker's and the firm's net return from the job match. Therefore, wages must satisfy the following conditions:

$w_{t}^{n}=\arg \max \left(p_{t}-w_{t}^{n}\right)^{1-\beta}\left(w_{t}^{n}-b_{t}\right)^{\beta}$

$w_{t}^{d}=\arg \max \left(p_{t}\left(1-\varepsilon-\theta_{t}\right)-w_{t}^{d}\right)^{1-\beta}\left(w_{t}^{d}+\alpha w_{0}^{d}-b_{t}-\alpha w_{0}^{d}\right)^{\beta}$

Notice that the disability pension, $\alpha w_{0}^{d}$ appears in the payoff, $w_{t}^{d}+\alpha w_{0}^{d}$, as well as in the outside option, $b_{t}+\alpha w_{0}^{d}$, of the weighted net return of the disabled worker because

\footnotetext{
${ }^{8}$ The temporary component of the wage loss can also be related to the ability to adapt to the disability condition. For a discussion, see for example Wu (2001), Oswald and Powdthavee (2008) and more recently Braakmann (2012) and Bayer and Juessen (2012).
} 
disability benefits are not contingent to the working status. Nash bargaining between the worker and the firm will always lead to agreement and the negotiated wages will be

$w_{t}^{n}=\beta p_{t}+(1-\beta) b_{t}$

$w_{t}^{d}=\beta p_{t}\left(1-\varepsilon-\theta_{t}\right)+(1-\beta) b_{t}$

The difference between expression (3) and (4) generates the following wage gap

$w_{t}^{n}-w_{t}^{d}=\beta p_{t}\left(\varepsilon+\theta_{t}\right)$

Expression (5) shows that the wage gap of a disabled worker depends on a permanent and a transitory productivity gap. The permanent component $\varepsilon$ is due to the disability condition after the disability shock while the transitory component is related to the presence of assimilation costs for being in a different job or professional activity, which reduces the implicit bargaining power of the disabled employee. ${ }^{9}$ Thus, equation (5) suggests that the wage gap will be lower after some work experience in the new job. In particular, we expect that $\lim _{t \rightarrow \infty} \theta_{t}=0$. However, the permanent wage gap will remain over time.

\section{Empirical strategy: Average Treatment Effect on the Treated}

As explained above, we want to estimate how much the wages change, on average, for those individuals who become disabled due to an exogenous disability shock, compared to the hypothetical state of not having received the disability shock that causes the disabling condition. One of the main problems in measuring this change is the simultaneous determination of being disabled and wages. In particular, we want to know what would have happened to that individual if he or she had not become disabled. As we do not have that information, we make use of matching methods to

\footnotetext{
${ }^{9}$ This permanent component of the wage gap can also include discrimination related to the disability status (see for example Malo and Pagán (2012).
} 
allow for the counterfactual approach, associated with treatment effects techniques for program evaluation.

Formally, let $D=1,0$ indicate if the individual is actually treated or not. In our case, if the individual becomes disabled or not. Let $X$ be the set of observed characteristics and $W_{1 i}$ and $W_{0 i}$ be the potential salaries of interest if the individual is treated or nontreated, respectively. The notion of "potential" is used to emphasize that only one of $W_{1 i}$ or $W_{0 i}$ is observed for every individual in the sample.

In this context we want to measure the Average Treatment Effect on the Treated (ATET), that is given by the following expression:

$$
A T E T=\vartheta=E\left\lfloor W_{1 i}-W_{0 i} \mid D_{i}=1\right\rfloor=E\left\lfloor W_{1 i} \mid X, D_{i}=1\right\rfloor-E\left\lfloor W_{0 i} \mid X, D_{i}=1\right\rfloor
$$

Clearly $\vartheta$ is not identified by the data, since we observe each individual in one of the possible states in each moment in time. Therefore, we do not observe the counterfactual. If we assume that the probability of becoming disabled is random, we could solve this problem by using the control group as a counterfactual. However, even though we have only taken the individuals that become disabled due to an accident, it could happen that those types of accidents that leave the individual impaired would occur in certain professions or sectors more than in others.

Therefore, our empirical strategy relies on the fact that we have sufficient information on the characteristics of the individual and the type of job that he or she has had before the disabling condition occurs. In this context, we use the Propensity Score Matching to create subgroups where the treated and control individuals do not differ before the shock and then we use different matching techniques to compare the individual in the treated group that is most similar to an individual in the control group. Such method is attractive because it represents an improvement compared to other parametric and semiparametric approaches to program evaluation since it avoids many potential biases due to model specification. ${ }^{10}$

In particular, our conditional independence assumption is:

$$
\left(W_{1 i}, W_{0 i}\right) \perp D \mid X
$$

\footnotetext{
${ }^{10}$ See Heckman and Horz (1989), Heckman, Ichimura and Todd (1997) and Blundell and Costa Dias (2002) are just some of the articles that explain how to evaluate certain treatments (in our case disability) using matching procedures.
} 
This assumption, which is known as selection on observables, was introduced by Rubin (1973, 1974) and Rosenbaum and Rubin (1983, 1984).

\section{Database and sample selection}

The study will use the Continuous Sample of Working Lives ("Muestra Continua de Vidas Laborales", MCVL) which is a microeconomic dataset based on administrative records provided by the Spanish Social Security Administration. It contains a random sample of $4 \%$ of all the individuals who, at some point during 2010, had contributed to the social security system (either by working or being on an unemployment scheme) or had received a contributory pension. ${ }^{11}$ The random sample selected contains over one million people.

There is information available on the entire employment and pension history of the workers, including the exact duration of employment, unemployment and disability pension spells, and for each spell, several variables that describe the characteristics of the job or the unemployment/disability benefits. There is also some information on personal characteristics such as age, gender, nationality and level of education.

For the treatment group, we select all individuals that become partially disabled due to an exogenous disability shock (accident) between 1996 and 2010. We do not include individuals that become totally disabled as the definition of total disability stresses that this group of individuals is not able to develop any kind of job. As our interest lies in estimating the wage (or productivity) lost due to the disabling disability shock, we exclude total disability holders from our sample. For the group of partially disabled individuals due to an exogenous disability shock, we include the wage of June of the year before becoming disabled as well as the wage that they are earning each June of each year that they are in the disability rolls and working on June 15th. Of course, not all individuals in the disability system are effectively working but they are all legally allowed to work because they are in the partial disability scheme. We also have information on the amount of disability benefits that they receive and we will use this information in some of our estimations.

\footnotetext{
${ }^{11}$ This means that the only individuals that are missing from this database are those who were inactive in 2010and did not receive any kind of contributory benefit (such as disability, orphan, widow, etc...). Furthermore, the sample is representative for 2010 but, as exit from the disability system is extremely low, we belief that the sample is also representative for the other years included in the analysis.
} 
With respect to the control group, we include a $10 \%$ random sample of everybody who is in our database between 1996 and 2010 and who will never receive disability benefits (due to any reason, common illness or accident). ${ }^{12}$ We select the employment status of each of these individuals on $15^{\text {th }}$ June of each year and we use the wage of June of each year that they are reported as working.

The selected sample contains 125.717 individuals (1.120.607 person-year observations in total), 71.917 of them are men while 53.800 are women. 2.762 of these individuals in our sample move to disability benefits due to an exogenous disability shock at some point between 1996 and 2010 and are, thus, our treatment group while 122.955 individuals never become disabled in our sample period and constitute our control group. We have selected such a large control group in order to ensure a good matching process and to make sure that we maximize the options of finding a similar individual in our control group for each individual that we have in the treatment group.

\section{Constructing the treatment and control groups}

In order to construct the treatment and control groups we use the MCVL and we follow a similar methodology as in Lechner and Vazquez-Alvarez (2004) and García-Gomez and López-Nicolás (2006). In particular, our treated group is formed by individuals who were non-disabled in $t=1$, become partially disabled by an exogenous disability shock (accident) in $t=2$ and continue being partially disabled in $t=3 .{ }^{13}$ As explained before, we consider only individuals that become disabled due to an accident to avoid individuals that start receiving disability benefits due to a common illness, because these disabled individuals may already have a reduced labor income at $t=1$, before becoming officially disabled, and that would bias our results. We want similar individuals in $t=1$, in the moment that we construct the propensity score. Therefore, we follow the following strategy:

(1) We consider a window of three years for each observed individual. Therefore, with annual date we require at least three waves to generate a sequence. In our case, we have 14 possible sequences of three years, because our data set covers the period 1996-2010.

\footnotetext{
${ }^{12}$ We take a $10 \%$ random sample as we have too many individuals in the original sample.

${ }^{13}$ Only $1.1 \%$ of individuals stop receiving partial disability benefits in our sample. Therefore, we consider partial disability as an absorbing state as exit from the partial disability system is very low.
} 
(2) For each sequence we select individuals who are healthy (not disabled) and are employed at $t=1$.

(3) Our treatment group are individuals who meet the selection criteria (2) and also become disabled due to an exogenous disability shock at $t=2$ and remain disabled at $t=3$. The sequence of health status for these individuals is No Disabled, Disabled, Disabled (ND,D,D).

(4) The control or comparison group are individuals who meet selection criteria (2), but in this case continue to be non-disabled both in $t=2$ as in $t=3$. Therefore they experienced the sequence No Disabled, No Disabled, No Disabled (ND,ND,ND). Table 2 shows the dynamics of the data, the formation of the sequences and the possible combinations between the treated and control samples over time. ${ }^{14}$

(5) We match individuals in the treated and control groups with the propensity score in $t=1$, where both individuals were non-disabled. We use: age, age squared, professional category, sequence, sex, nationality and wages at $t=1$ as regressors. Since we use a longitudinal database we can use the outcomes before the individual becomes or does not become disabled in the vector of conditioning variables (for example, the wages in $t=1$ ).

Table 2: Definition of treatment and control groups

\begin{tabular}{|c|c|c|c|c|c|c|c|c|}
\hline \multicolumn{9}{|c|}{ TREATMENT SAMPLE: ND,D,D } \\
\hline Sequence & 1994 & 1995 & 1996 & 1997 & $\ldots \quad 2007$ & 2008 & 2009 & 2010 \\
\hline 1 & ND & D & D & & & & & \\
\hline 2 & & ND & D & D & & & & \\
\hline$\ldots$ & & & & & & & & \\
\hline 13 & & & & & ND & D & D & \\
\hline 14 & & & & & & ND & D & D \\
\hline \multicolumn{9}{|c|}{ CONTROL SAMPLE: ND,ND,ND } \\
\hline Sequence & 1994 & 1995 & 1996 & 1997 & .. 2007 & 2008 & 2009 & 2010 \\
\hline 1 & ND & ND & ND & & & & & \\
\hline 2 & & ND & ND & ND & & & & \\
\hline .... & & & & & & & & \\
\hline 13 & & & & & ND & ND & ND & \\
\hline 14 & & & & & & ND & ND & ND \\
\hline
\end{tabular}

\footnotetext{
${ }^{14} \mathrm{An}$ individual who is in the control group in one sequence, can be a control unit for any given sequence and count as independent observation for each of the different sequences. However, individuals who appear as treatment unit can only appear in one sequence, because, once he or she becomes disabled, he or she will remain disabled permanently. Only once the individual can experience the sequence ND,D,D
} 


\section{Descriptive statistics}

Table 3 presents samples size for the treated and control groups for the different subsamples that we consider in our estimations.

Table 3: Samples size for treated and control groups.

\begin{tabular}{|l|c|c|}
\hline & Treated (ND, D, D) & Control (ND, ND, ND) \\
\hline $\begin{array}{l}\text { Conditional on working in the first } \\
\text { year of the sequence. }\end{array}$ & 1718 & 530759 \\
\hline $\begin{array}{l}\text { Conditional on working in the first and } \\
\text { third year of the sequence }\end{array}$ & 356 & 473627 \\
\hline $\begin{array}{l}\text { Conditional on working in the first, the } \\
\text { third, the forth......and the seventh } \\
\text { year of the sequence }\end{array}$ & 189 & 310536 \\
\hline
\end{tabular}

As we can observe in the table 3 , the number of observations that we have in the control group is very high, this is because we have a very large sample since the data come from the social security registers and also because an individual who is in the control group in one sequence, can be a control unit for any given sequence and count as independent observation for each of the different sequences. Having so many observations in the control group and using our matching technique allows us to choose the individual in the control group that is more similar in characteristics to the treated individual before the shock occurs.

The first row of table 3 shows the number of observations that we have when we analyse the effects of the disabling condition independently on whether the individual works the shock occurs. In this case we condition only on working before the shock and we analyse the effects on the amount of wages plus the disability benefits. The second row shows the number of observations we have if we restrict our sample to include only individuals who have worked in the year before and the year after the shock occurs. Finally, in the last column we have the number of observations used to explore what happens to the wage gap over time. The number of treated individuals is small because the condition is very restrictive, are individuals who become disabled at $t=2$ and continue being disabled at $t=3, t=4, t=5, t=6$ and $t=7$. 
Table 4: Descriptive statistics of different wage measures.

\begin{tabular}{|c|c|c|c|c|}
\hline & \multicolumn{2}{|c|}{ Treated } & \multicolumn{2}{|c|}{ Control } \\
\hline & Mean & Std Dev & Mean & Std Dev \\
\hline \multicolumn{5}{|c|}{ Conditional on working in $t=3$} \\
\hline Wage 1 in $t=3$ & 1389,15 & 1267,22 & 1584,55 & 995,76 \\
\hline Wage1 + Pension & 2282,19 & 1390,74 & 1584,55 & 995,76 \\
\hline Wage 2 in $t=3$ & 1204,43 & 658,99 & 1322,42 & 1041,28 \\
\hline Wage2 + Pension & 2097,46 & 873,95 & 1322,42 & 1041,28 \\
\hline \multicolumn{5}{|c|}{ Independently if they work in $t=3$} \\
\hline Wage1 + Pension & 1283,2 & 869,89 & 1502,63 & 1026,02 \\
\hline Wage2 + Pension & 1244,5 & 728,21 & 1292,9 & 1020,69 \\
\hline
\end{tabular}

Table 4 shows some descriptive statistics about the different wage measures that we use in the estimations. As we can see, wages in the treated group are lower than wages in the control group after the shock. When we add the disability benefits (pension), we obtain different results, depending on whether we condition the sample to include only those who work at $t=3$ or not. If we condition on working at $t=3$, something that the partial disabled can do, we obtain that the sum of the benefits and wages is greater for the treated than for the control group. However, taking into account all the disabled in the sample, independently of whether they work or not, the sum of wages plus the pension is less for the treated group. This result shows how some disabled people, although the law allows them to work, decide not to work and live only with the benefit that they receive from the disability system.

\section{Results}

In this section we calculate the impact of becoming disabled on different measures of wages. We try to answer the following question: What is the effect of receiving a 
disability shock and becoming disabled on the wages of the disabled compared to the wages in the hypothetical state of not having become disabled?

We estimate ATET effects following Becker and Ichino (2002), Abadie and Imbens (2002) and Abadie et al. (2004). First, we estimate the propensity score (the probability of being in the treatment group) by a probit specification due to the fact that we have two possible states (ND,D,D versus ND,ND,ND). We used age, age squared, professional category, sequence, sex, nationality and wages at $t=1$ as explanatory variables. The specification passes the "balancing hypothesis". ${ }^{15}$ This means that there are no systematic differences in observable characteristics between the treated and control groups once we condition on the propensity score. After that, we match treated and control individuals using different methods. In particular, we use the: (i) nearest neighbor matching and the (ii) kernel matching method. There is no a priori element to prefer one of these methods. Therefore, we present the results of all estimates to assess the robustness of the results.

\subsection{Effects of becoming disabled on wages.}

Table 5 presents the estimates of the ATET of disability on different measures of earnings in $t=3$, the year after the treated individuals become disabled. We use two different measures of earnings: the monthly average wage in June (we call that measure wage 1$)^{16}$ and a monthly average of the wage of all the year (we call that measure wage 2). ${ }^{17}$

In fact, what we don't use wages as such but a proxy for wages, the contributory base over which the contributions to the Social Security administration are calculated and paid. As it often occurs with Social Security records, wages in the MCVL are top- and bottom-coded, that is, they are censored. Although for the entire MCVL this is a significant problem as Bonhomme and Hospido (2009) mention, such an issue is likely not to be empirically relevant in our case as wages are censored only for very few observations.

\footnotetext{
${ }^{15}$ We also have tried with other variables like education, sector of activity, but at the end we have selected those who generate a better match.

${ }^{16} \mathrm{We}$ take into account the number of days worked during the month. In fact, we divide the wage received in June by the total number of days worked. After that, we multiply this figure by 30 in order to have a monthly wage.

${ }^{17}$ In this case we sum the wage received in all the months worked and then we divide this wage by the total number of month worked to obtain a monthly measure.
} 
All the estimations using both wage measures show a significant reduction in the monthly wage for the disabled due to the disabling condition. As our theoretical model presented in Section 2 suggests, that reduction is probably due both to a fall in productivity generated by the fact of becoming disabled (permanent productivity shock) and also by a temporary productivity shock related to the fact that these individuals have to change jobs and have, therefore, a learning process in the new job. In section 5.3 we will develop this point further.

Table 5: Effects of disability on wages at $\mathrm{t}=3$

\begin{tabular}{|ccc|}
\hline & $\begin{array}{c}\text { Nearest-Neighbor } \\
\text { Matching }\end{array}$ & $\begin{array}{c}\text { Kernel matching } \\
\text { method }\end{array}$ \\
\hline Wage 1 & -293.38 & -342.21 \\
& $(97.83)$ & $(81.99)$ \\
Wage 2 & -516.37 & -495.83 \\
& $(69,41)$ & $(46.19)$ \\
\hline
\end{tabular}

Note: Money figures are expressed in 2010 euros. Bootstrapped standard errors in parentheses.

For instances, using our first measure of wage and the nearest neighbor matching method, the reduction of the wage of the disabled is 293 euros per month expressed in constant terms at 2010 prices. If we use the kernel matching method, the reduction is a bit higher, 342 euros per month. As we have seen above that the average wage for the individuals working at $\mathrm{t}=3$ is 1389,15 euros per month, this wage gap represents between $21 \%$ and $24 \%$ of the wage of a disabled worker (depending on the matching method applied). The reduction is a bit higher when we consider the second measure of wages with both matching methods and represents between 41 and $42 \%$ of the average wage of the disabled.

\subsection{Does the disability benefit offset this gap?}

An important point is whether the benefits or pensions that are received by these disabled individuals are able to compensate the lower wages that they get. Therefore, this subsection tries to discern to what extend the social security provisions compensate for the loss of wage that we observe in Section 8.1. In other words, we try to see if, once we take into account the amount earned in disability benefits, the income gap between our treated group and our control groups is maintained. 
Since the disability pension can be received independently of the working status of the individual, we do the exercise for two subsamples. In Table 6 we work with the subsample of disabled individuals who continue working after the shock of becoming disabled. Therefore, we have a sample of individuals (in the treated and in the control group) that work in $t=3$. Instead, in table 7 we do not condition the disabled to work in $t=3$ and therefore our sample of disabled individuals includes individuals that may or may not work. In both tables we consider the sum of wages, if they work, plus the disability benefits.

Table 6: Effects of the disability on the wages plus pension

for the disabled who work in $\mathrm{t}=3$

\begin{tabular}{|ccc|}
\hline & $\begin{array}{c}\text { Nearest- } \\
\text { Neighbor } \\
\text { Matching }\end{array}$ & $\begin{array}{c}\text { Kernel } \\
\text { matching } \\
\text { method }\end{array}$ \\
\hline wage 1+ pension & 607.63 & 558.81 \\
& $(104.50)$ & $(85.99)$ \\
wage 2+ pension & 384.63 & 405.18 \\
& $(78.57)$ & (57.08) \\
\hline
\end{tabular}

Note: Money figures are expressed in 2010 euros. Bootstrapped standard errors in parentheses.

Table 7: Effects of the disability on the wages plus pension for all the disabled, independently if they work in $t=3$

\begin{tabular}{|lll|}
\hline & $\begin{array}{l}\text { Nearest- } \\
\text { Neighbor } \\
\text { Matching }\end{array}$ & $\begin{array}{l}\text { Kernel } \\
\text { matching } \\
\text { method }\end{array}$ \\
\hline wage 1+ pension & -287.87 & -359.74 \\
& $(32.09)$ & $(25.41)$ \\
wage 2+ pension & -320.54 & -404.64 \\
& $(29.14)$ & (24.13) \\
\hline
\end{tabular}

Note: Money figures are expressed in 2010 euros. Bootstrapped standard errors in parentheses.

In table 6 we note that, when we condition on the subsample of individuals working in $t=3$, the sum of the wage plus the disability pension is greater in the treated group than in the control group. This means that the pension for this subgroup of disabled workers more than offsets the drop in wages observed in Section 5.1, regardless of the matching method and the definition of wages (wage 1 or wage 2) that we use.

However, when we do not condition on the fact that individuals work in $t=3$, we note in table 7 that the benefits do not offset all the fall in income. These individuals, in the 
hypothetical case of not having become disabled, would have obtained a higher income by just working.

\subsection{What happens with the gap over time?}

In this section, we consider a longer period sequence in order corroborate the hypothesis of our theoretical model that part of the wage gap between our treated and control group should decrease over time due to the reduction in the temporary productivity gap.

As explained before, partially disabled worker who receive a pension can continue working but not in the same job than they had before the disability shock. Therefore, they have to change the job after being granted the disability benefits. In the new job, we will expect a drop in their productivity and therefore, we expect a drop in the wages that they receive. This drop in productivity, as our model in section 3 has shown, can be broken down into two elements: first, a permanent fall due to the fact of becoming disabled, with a permanent fall in the wages associated to those individuals; and second, a transitory fall in productivity caused by the fact that the new job requires a learning process. We expect that the transitory fall in productivity, and therefore in wages will tend to disappear over the years.

Therefore, in this section we want to see how much of the wage gap observed in Section 5.1 is due to a permanent fall in productivity (due to the disability shock experienced) and what part of the fall of the productivity is transitory.

We restrict our sample to individuals who work from $t=3$ to $t=7$ to ensure that we are analysing the fall in wages for the same individuals. We want to see if the drop in wages remains constant or decreases with time. We also want to see if the fall in wages is continue or if, at some point, it stabilizes and reaches a constant value.

Table 8 shows that, for the two measures of wages and for the two matching methods used, wages for disabled workers are lower than wages in the control group. 
Table 8: wage gap over time: permanent and transitory fall in productivity

\begin{tabular}{|l|lllllll|}
\hline \multicolumn{9}{|c}{} & \multicolumn{1}{c}{$\boldsymbol{t}=\mathbf{3}$} & $\boldsymbol{t}=\mathbf{4}$ & $\boldsymbol{t}=\mathbf{5}$ & $\boldsymbol{t}=\mathbf{6}$ & $\boldsymbol{t}=\mathbf{7}$ \\
\hline & \multirow{2}{*}{$\begin{array}{l}\text { Nearest- } \\
\text { Neighbor } \\
\text { Matching }\end{array}$} & Wage 1 & $-261,02$ & $-210,79$ & $-172,36$ & $-152,13$ & $-151,46$ \\
& & $(101.84)$ & $(105.03)$ & $(106.3)$ & $(110.93)$ & $(106.15)$ \\
& Wage 2 & $-409,57$ & $-392,24$ & $-379,58$ & $-231,9$ & $-230,94$ \\
& & $(106.17)$ & $(110.78)$ & $(106.68)$ & $(110.63)$ & $(111.25)$ \\
\hline & \multirow{2}{*}{$\begin{array}{l}\text { Kernel } \\
\text { matching } \\
\text { method }\end{array}$} & Wage 1 & $-361,84$ & $-353,79$ & $-329,98$ & $-315,81$ & $-315,03$ \\
& & $(78.19)$ & $(88.56)$ & $(105.42)$ & $(84.87)$ & $(93.59)$ \\
& Wage 2 & $-480,03$ & $-453,05$ & $-421,74$ & $-372,84$ & $-371,72$ \\
& & $(65.44)$ & $(88.74)$ & $(70.90)$ & $(72.47)$ & $(98.91)$ \\
\hline
\end{tabular}

Note: Money figures are expressed in 2010 euros. Bootstrapped standard errors in parentheses.

We tested for different periods of years and we observe that the pay gap between the disabled and the non-disabled individuals falls over time. This means that the transitory drop in productivity is disappearing. However, we observe a constant wage gap associated with the permanent fall in productivity. Table 8 shows that for $t=6$ and $t=7$ (ie, 4 and 5 years after having become disabled) the difference in the wages becomes permanent and it remains relatively constant.

\section{Conclusions}

Despite several policies that aim at ensuring that disabled individuals have the same labour market opportunities than their non-disabled counterparts (such as antidiscrimination and labour promotion policies), Spain is characterized by having very low employment rates for disabled individuals when compared to other OECD countries. Therefore, in this paper we explore whether disabled workers in Spain have yet another disadvantage in terms of labour market opportunities by testing whether the onset of an unexpected disabling condition does also entail reduced earnings for the disabled. At the same time, we are also interested in analysing whether this wage gap with respect to their non-disabled counterparts is permanent in time or is reduced over time. In other words, we want to know if disabled individuals are able to "catch up" in terms of wages lost due to the disabling condition.

In order to do that, we present both a theoretical and an empirical model that allows us to identify the effects of disability on wages and the channels underlying this relationship. In the theoretical wage gap model we assume that the wage gap of a 
disabled worker depends on a permanent and a transitory productivity gap. The permanent component is due to the disability condition after the disability shock while the transitory component is related to the presence of assimilation costs for being in a different job or professional activity, which reduces the implicit bargaining power of the disabled employee. Thus, the model predicts that the wage gap will be lower after some work experience in the new job (reduction of the temporary component of the wage gap) but that the permanent wage gap will remain.

We proceed by testing this theoretical hypothesis with an empirical model in which we want to estimate how much wages change, on average, for those individuals who become disabled due to an exogenous disability shock, compared to the hypothetical state of not having received the disability shock that causes the disabling condition. We also empirically estimate the evolution of this wage gap over time in order to check whether the predictions of the theoretical model are fulfilled. As one of the main problems in measuring this change is the endogeneity of the disability status and the wages, we only include in our sample individuals that become disabled due to an accident and estimate the Average Treatment Effect on the Treated (ATET). Therefore, we want to know what would have happened to that individual if he or she had not become disabled (counterfactual) and, as we do not have that information, we make use of matching methods. In particular we estimate the effect of disability on wages by matching on the propensity score.

In all our specifications, we find that the reduction of the wage for the disabled is between 293 and 342 euros per month expressed in constant terms at 2010 prices (between 21 and 24\% of the average wage of a disabled worker) but this reduction is more than offset when we take as the income measure both the wage and the disability benefits that they get for the group of individuals that work. For the entire group of disabled individuals (the ones that work and the ones that do not have a job), we still find a drop in income for the disabled relative to the non-disabled individuals even when we add up the wage and the benefits. Therefore, those individuals would have obtained a higher income by just working in the hypothetical case of not having suffered the disabling condition. Finally, we observe that the pay gap between the disabled and the non-disabled individuals falls over time as predicted in the theoretical model so that the transitory drop in productivity is disappearing. However, we observe a 
constant wage gap associated with the permanent fall in productivity predicted in the theoretical model that remains constant over time.

\section{References}


Abadie A, Drukker D, Herr H, Imbens G. 2004. Implementing matching estimators for average treatment effects in Stata. Stata Journal 4: 290-311.

Abadie A, Imbens G. 2002. Simple and bias-corrected matching estimators for average treatmen efects in STATA. Stata Journal 1 (1): 1-18.

Brakmann, Nils (2012): "The consequences of own and spousal disability on labor market outcomes and subjective well-being: Evidence from Germany", Review of Economics of the Household, forthcoming.

Bayer, C. and Juessen, F. (2012): "Happiness and the persistence of income shock", IZA Discussion Paper No. 6771.

Becker S, Ichino A. 2002. Estimation of average treatment effects based on propensity scores. Stata Journal 2(4): 358-377.

Blundell R, Costa Dias M. 2002. Alternative approaches to evaluation in empirical microeconometrics. Portuguese Economic Journal 1: 91-115.

Bonhomme, S., and L. Hospido (2009): "Using Social Security Data to Estimate Earnings Inequality," Mimeo.

Charles, K. K. 2003. The Longitudinal Structure of Earnings Losses among WorkLimited Disabled Workers, Journal of Human Resources, 38(3), 618-46.

Contoyannis P, Rice N. 2001. The impact of health on wages: Evidence from the British Household Panel Study. Empirical Economics 26 (4): 599-622.

Garcia Gomez P, López Nicolás A. 2006. Health Shocks, Employment and Income in the Spanish Labour Market. Health Economics 15: 997-1009.

Heckman J, Hotz J. 1989. Choosing among alternative methods for estimating the impact of social programs: The case of manpower training. Journal of the American Statistical Association 84: 862-874.

Heckman J, Ichimura H, Todd P. 1997. Matching as an econometric evaluation estimator: evidence from evaluating a job training program. Review of Economics Studies 64: 605-654.

Kidd M, Sloane P, Ferko I. 2000. Disability and labour market: an analysis of British males. Journal of Health Economics 19: 961-981.

Lechner M, Vazquez-Alvarez R. 2011. The Effect of Disability on Labour Market Outcomes in Germany. Applied Economics 43: 389-412.

Lundborg P, Nilsson M, Vikström J. 2011. Socioeconomic Heterogeneity in the Effect of Health Shocks on Earnings: Evidence from Population-Wide Data on Swedish Workers. IZA Working Papers No.6121. 
Malo, M.A. and Pagán, R. (2012): "Wage differentials and disability across Europe: Discrimination and/or lower productivity", International Labour Review, 151(1-2): 4360 .

Meyer, B. D., and Mok, W.K.C. 2008. Disability, Earnings, Income and Consumption, mimeo, University of Chicago.

Mok, W. K.C., Meyer, B. D., Charles, K. K. and Achen, A. C. 2008. A Note on the Longitudinal Structure of Earnings Losses among Work-Limited Disabled Workers. Journal of Human Resources, 43(3), 721-8.

OECD. 2009. Sickness, Disability and Work: Keeping on Track in the Economic Downturn: Background Paper.

Oswald, A.J. and Powdthavee, N. (2008): "Does happiness adapt? A longitudinal study of disability with implications for economists and judges", Journal of Public Economics, 92(5-6): 1061-1077.

Rubin DB. 1973. Matching to remove bias in observational studies. Biometrics 29: 159183.

Rubin DB. 1974. Estimating casual effects of treatments in randomised and nonrandomised studies. Journal of Educational Psychology 66: 688-701.

Rosenbaum P, Rubin DB. 1983. The central role of the propensity score in observational studies for causal effects. Biometrika 70: 41-55.

Rosenbaum P, Rubin DB. 1984. Reducing bias in observational studies using subclassification on the propensity score. Journal of American Statistical Association 79: 516-524.

Walker I, Thompson A. 1996. Disability, wages and labour force participation: Evidence from UK panel data. Keele Department of Economics Working Paper No. 96/14.

Wu, S. (2001): "Adapting to heart conditions: a test of the hedonic treadmill", Journal of Health Economics, 20(4): 495-507. 